\title{
Human error analysis: A case study in a Tyre Tube Polymer Processing Industry
}

\author{
Skanda M.G \\ Research Scholar \\ Department of Industrial and Production Engineering, \\ SJCE, Mysore-570006 \\ Dr. V. Ramesh \\ Professor \\ Department of Industrial and Production Engineering, \\ SJCE, Mysore-570006 \\ D. Arun Kumar \\ Associate Professor, \\ Department of Industrial and Production Engineering, \\ SJCE, Mysore-570006
}

\begin{abstract}
Most of the industrial accidents and incidents are attributed to human errors. Many studies on industrial safety have proposed theories and solutions to mitigate human errors by improving the design and environmental aspects of the organizations. However, human error also needs to be studied from the point of view of cognitive mechanisms of workers and operators in critical industrial environment. In this regard this paper discusses exploratory study of human error in a polymer company in Mysore city. The literature review showed that human operators are always at the sharp end of the system and are prone to errors, which leads to accidents and incidents. Human fallibility is unavoidable. The primary data was collected through informal interview method involving shop floor supervisors and process operators. Separate interviews were conducted for supervisors and operators to assess the safety climate in the organization. Interview with the process operators revealed that the mixing, straining and milling sections of the organization are considered to be safety critical. All the three sections mentioned are highly procedure driven in carrying out the process operations and required safety precautionary measures in doing each task. A retrospective task analysis of the mixing, straining and milling sections were carried out and types of errors and causes of errors were identified. This paper also asserts the importance of taxonomic approach in identifying the human errors in industrial setups.
\end{abstract}

Key words: Safety critical domains, Human error, Human reliability, Taxonomy, Industrial accidents, Task analysis

\section{INTRODUCTION}

Workplace safety is becoming a paramount important aspect for organizations to prevent industrial accidents and incidents specifically in hazardous and critical sectors. Many safety training programs are being conducted by Government bodies as well as private consultancies to impart safety education to Industrial employees. It is a requirement under Factories Act, 1948 [1] that every organization shall ensure safety and welfare of all workers while they are at work in the factory which implies that factory authorities should take measures to establish identifying hazards and that are eliminated or reasonably controlled. Section 41A of the act, which deals with site appraisal committee and rule made there under, requires risk analysis report for which hazards are to be identified. A number of other enactments also require risk analysis report. Therefore, hazard identification is essential for:

1. Statutory compliance

2. Minimize loss exposure and risk

3. Better safety management

In spite of safety policies, rules \& regulations, many industrial accidents and incidents are being reported from different sectors. In most of the cases accidents and incidents are attributed to 'human error' for unsafe acts. Many studies on industrial safety have proposed theories and solutions to mitigate human error by improving the design and environmental aspects of organizations. There is a need to systematically study phenomenon of human error 
from the point of view of cognitive mechanisms of industrial workers/operators working in critical industrial environment.

Current paper aims to investigate the nature of relationship between cognitive variables and deviant actions performed by the workers which lead to errors in turn may lead to accidents and incidents in industrial environments. Further, Investigation of these variables will help to develop taxonomy of human errors in identified safety critical domains. Also, paper suggests that analysis of these errors provides the basis for developing a model for human reliability and helps in designing safety recommendations which can be adopted in safety education and management programs.

\subsection{Defining human error}

\section{LITERATURE SURVEY}

Oxford English dictionary defines the term error as the state or condition of being wrong in conduct or judgment. More often we hear the term human error in domains such as Aerospace, railroad, healthcare as well as in Industrial setups. Since most of these domain activities comprise of workers operating in a complex environment in which safety is a paramount importance any deviation from the operations will lead to incidents and accidents.

Many accident and incident reports may interpret the cause of accidents as human error but there is a need to study and analyze the mechanism of human error and its manifestation in safety critical domains. Clearly defining the human error and building taxonomy of the human error will be helpful for safety professionals and the like professionals to investigate the cause of human error more precisely in accident-incident analysis.

Literature shows that human factors researchers and accident analysts have been working on developing tools for human reliability in managing unsafe acts. Some of the human factors researchers, cognitive scientists, and other domain specialists have tried to define human error and its mechanism in various setups. We will see some of the most cited definitions given by experts in these fields

According to David Meister [2] a human factor expert defines human error from psychological functions that are fundamental to human behavior "A failure of a common sequence of psychological functions that are basic to Human behavior Stimulus, organism and response. When any element of the Chain is broken; a perfect execution cannot be achieved due to failure of perceived Stimulus, inability to discriminate among various stimuli, misinterpretation of meaning of stimuli, not knowing what response to make to a particular stimulus, physical inability to make the required response and responding out of sequence".

Swain and Guttmann [3] in specific to nuclear power plants they define human error as "An error is an out of tolerance action, where the limits of tolerable performance are defined by the system"

Hollanagel [4] proposes human error as 'erroneous action' rather than 'human error'. An erroneous action can be defined as an action which fails to produce the expected result and/or which produces an unwanted consequence. The problem, according to him, is that human error can be understood in different ways. Firstly, it can refer to the cause of an event, so that after an accident occurs, it is often reported that it was due to human error. Human error can also be a failure of the cognitive (or thinking) processes that went into planning an action or sequence of actions, a failure in execution of the action or a failure to carry out the action at all. Erroneous action defines what happened without saying anything about why it happened.

A pioneer in human error field James Reason [5] defines human error as a "generic term to encompass all those occasions in which a planned sequence of mental or physical activities fails to achieve its intended outcome, and when these failures cannot be attributed to some chance agency".

Safety audits and safety awareness program are not designed around any theoretical framework of human error. Unfortunately, attribution accident analysis culminates in human error. There is a need for new frame for accident and incident databases which can be restructured around human error taxonomic framework.

\subsection{Human error classification system}


The field of human reliability analysis (HRA) aims to identify the causes and sources of human errors and provide a numeric estimate of the likelihood of such errors. Many theories have been proposed to explain the human error in industrial environments and causes of accidents in industries. This review will focus on major themes related to human error classification systems.

In his book on human error R.B Whittingham [7] defines general meaning of taxonomy and explains the purpose of doing the classification system, according to him 'Human error can occur in a wide variety of types and forms and be manifested in almost infinite number of ways. To introduce some order into what might otherwise become a veritable forest of errors; attempts have been made by experts in the field to formulate ways of organizing errors into taxonomies. The definition of taxonomy, according to Collins English Dictionary, is 'a grouping based on similarities of structure or origin'. Taxonomies are usually applied in the biological sciences to classify animal or plant genera and species and to provide a framework of orders, families and sub-families. The purpose of human error taxonomy is exactly the same. However, as with animal plant species, there are many different ways of organizing human errors into taxonomies. The choice of taxonomy depends mainly on the purpose for which it is to be used.

There exist various taxonomies of human error classification schemes used in complex safety critical domains. Human error classification systems are used both pro-actively by anticipating the errors and retrospectively during the post-accident/incident investigations.

The three important most cited classification dominates human reliability literature are:, Reason's (1990) generic error modeling system[5] Norman's (1981) error categorization [6] and Rasmussen's skill, rule and knowledge error classification (1986) [8] . A brief summary of these approaches is given below.

\subsection{Norman's error categorization}

Norman, 1981[6] error classification scheme is based on diary study conducted for a sample of 1000 action slips. Norman assumed that human information processing system is meditated by processing structures known as "schemas". Norman's taxonomy is organized around three headings; each corresponds to a different type of slips.

Table1: Classification of errors [6]

\begin{tabular}{|c|c|}
\hline 1. Slips in the formation of intention & $\begin{array}{l}\text { a. Mode errors } \\
\text { b. Description errors }\end{array}$ \\
\hline 2. Slips that arises from faulty activation of schemas & $\begin{array}{l}\text { a. Unintentional activation } \\
\text { 1. Capture errors } \\
\text { 2. Data-driven activation } \\
\text { 3. Associative activation } \\
\text { b. Loss of activation } \\
\text { 1. Forgetting an intention } \\
\text { 2.Misordering the components of a sequence } \\
\text { 3. Leaving out steps in a sequence } \\
\text { 4. Repeating steps in a sequence }\end{array}$ \\
\hline 3. Slips that arise from the faulty triggering of active schemas & $\begin{array}{l}\text { a. False triggering } \\
\text { 1. Spoonerisms } \\
\text { 2. Blends } \\
\text { 3. Thoughts leading to actions } \\
\text { 4. Premature triggering } \\
\text { b. Failure to trigger } \\
\text { 1. Action pre-empted } \\
\text { 2. Insufficient activation } \\
\text { 3. Triggering conditions failed to match }\end{array}$ \\
\hline
\end{tabular}

\subsection{James Reason’s Generic Error Modeling System (GEMS)}


Apart from concentrating on 'slips' James Reason [5] developed error taxonomy incorporating lapses, mistakes and violations. Slips and lapses are characterized by attention failures and memory failures respectively. Slips and lapses are the examples of the unintended actions whereas mistakes are associated with intended action. A mistake occurs when an actor intentionally performs an action that is wrong. Therefore mistakes originate at the planning level, rather than the execution level, and can also be termed planning failures. Violations are more complex, and are categorized behaviors that deviate from accepted procedures, standards and rules. Violations can be either deliberate or unintentional [5].

Table.2: Basic error types with examples [5]

\begin{tabular}{|c|c|}
\hline Error Type & Example \\
\hline Slip (attention failure) & $\begin{array}{ll}\text { - } & \text { Misperception } \\
\text { - } & \text { Action intrusion } \\
\text { - } & \text { Omission of action } \\
\text { - } & \text { Reversal of action } \\
\text { - } & \text { Misordering of action } \\
\text { - } & \text { Mistiming of action }\end{array}$ \\
\hline Lapse (memory failure) & $\begin{array}{ll}- & \text { Omitting of planned actions } \\
\text { - } & \text { Losing place in action sequence } \\
\text { - } & \text { Forgetting intended actions } \\
\end{array}$ \\
\hline Mistake (intention failure) & $\begin{array}{ll}\text { - } & \text { Misapplication of good procedure } \\
\text { - } & \text { Application of a bad procedure } \\
\text { - } & \text { Poor decision making } \\
\text { - } & \text { Overconfidence }\end{array}$ \\
\hline
\end{tabular}

Reason makes the point that slips and lapses are likely to result from either inattention (e.g., failing to monitor performance at critical moments in the task, especially when the person intends to do something out of the ordinary - such as deviating from the normal procedure of operation) or over attention (e.g., monitoring performance at the wrong moments in the task). Whereas, Reason argues, mistakes are likely to result from either the misapplication of a good procedure (e.g., a method of performing a task that has been successful before in a particular context) or the application of a bad procedure (e.g., a method of performing a task that is "unsuitable, inelegant or inadvisable" at the most basic level [5] [10].

\subsection{Skill, Ruled, Knowledge based behavioral model for error classification}

According to Rasmussen [8] [9] errors are also affected by skill, experience and familiarity with the situation. Fig. 1 shows three levels of cognitive control, denoted as skill-based, rule-based, and knowledge-based, behavior.

Human action can be highly automatic (i.e. skill based), associative (i.e. rule-based), and analogous or exploratory (knowledge-based). Aspects of the task that are very familiar and routine will be largely automatic (i.e. skill-based behavior). Aspects of the task that are unfamiliar and rarely encountered will require effort and conscious attention (i.e. knowledge-based behavior). In between these extremes are aspects of the task that require identification and recall of the appropriate response which is stored in memory (i.e. rule-based behavior). 


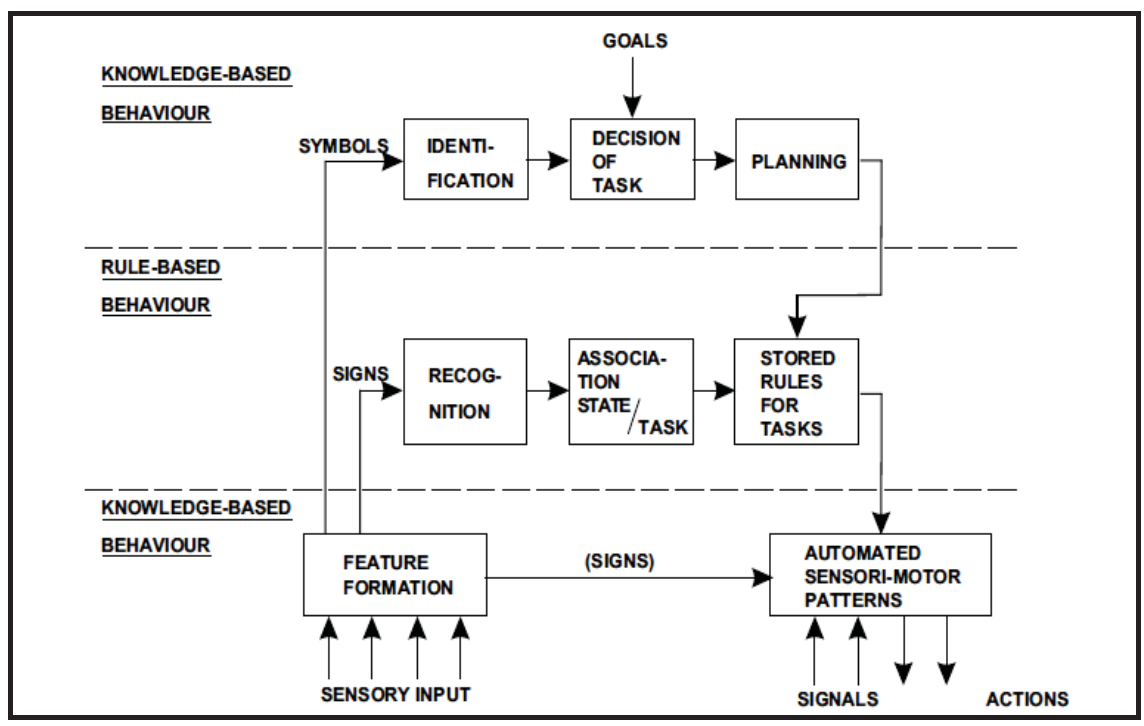

Figure.1: Three levels of performance of human operators (Adapted from J. Rasmussen's SRK model)

\section{CURRENT STUDY}

An exploratory study of human error in a tyre tube polymer company in Mysore city was carried out. The primary data was collected through informal interview method involving shop floor supervisors and process operators. Separate interviews were conducted for supervisors and operators to assess the safety climate in the organization.

Interview with the process operators revealed that the mixing, straining and milling sections of the organization are considered to be safety critical. All the three sections mentioned are highly procedure driven in carrying out the process operations and require safety precautionary measures in doing the each step of task. Also, past record showed that in straining section a worker lost his hand while replacing a mesh in a strainer.

A retrospective task analysis of the mixing, straining and milling sections were carried out and types of errors and causes of errors were identified. Classification of errors was done based on James Reason's generic error modeling system to identify and classify the error types. The summary of type of error and its characteristics and causes are summarized in the following table and table respectively.

Table 3: Types of error identified in tyre tube polymer processing organization

\begin{tabular}{|l|l|c|c|}
\hline & Process & Critical task description & Type of error identified \\
\hline 1. & Mixing & Manual feeding of raw material & Slip \\
\hline 2. & Straining & $\begin{array}{l}\text { Insertion of mesh } \\
\text { Feeding of raw } \\
\text { materials } \\
\text { Mesh replacement }\end{array}$ & Slip \\
\hline 3 & Milling & $\begin{array}{l}\text { Milling of stock } \\
\text { compound }\end{array}$ & Lapse based mistake \\
\hline
\end{tabular}

The summary of type of error and its characteristics and causes are summarized in the following table 
Table 4: Cause and Characteristics of errors

\begin{tabular}{|l|l|c|}
\hline $\begin{array}{l}\text { Error } \\
\text { type }\end{array}$ & Cause & Typical characteristics of error mechanism \\
\hline Slip & $\begin{array}{l}\text { Mismatching and Misordering } \\
\text { of procedure }\end{array}$ & $\bullet \quad$ Frequently performed action goes wrong \\
\hline Lapse & Forgetting intended action & $\begin{array}{l}\text { Error of omission due to memory lapse. Action in a } \\
\text { procedure is not intended }\end{array}$ \\
\hline Mistake & Poor decision making & $\bullet \quad \begin{array}{l}\text { Decision-making failures; errors of judgment. } \\
\text { Misapplication of a good rule or } \\
\text { application of a bad rule }\end{array}$ \\
\hline
\end{tabular}

From the table major types of errors which occur in three different sections of the plant and their typical characteristics of error mechanism have been listed. Study revealed that there is lack of safety measures and training to the employees in dealing with the critical operations in the sections considered. We assert that these types of error identification and documenting errors will further help the organizations to mitigate errors committed by the worker.

\section{DISCUSSION}

The current paper asserted the importance of taxonomic approach in the identification of human errors in industrial setups. The literature review showed that human operators are always at the sharp end of the system and are prone to errors, which leads to accidents and incidents.

Further, this paper argued on a premise that human fallibility is not avoidable but it can be prevented or its effect can be mitigated by proper understanding of the job and behavior of the operator in performing the task.

Research shows that there is a need to define the detailed nature of errors and develop the database comprising of industry specific accidents and incidents. A robust database of predictive errors based on previous case studies (retrospective analysis) and task analysis will help the safety professionals to identify and categorize the errors and will lead to a better management of errors through this database.

\section{CONCLUSION}

Based on the review of human reliability literature and exploratory case study - The need for taxonomic approach to human error has been discussed in the paper. Industry specific taxonomy will help the professionals to have a ready reckoner checklist when conducting a safety audit. The limitation of this study is, it is exploratory and qualitative in nature. Probabilistic models can be used to quantify human error which helps in predicting the human error proactively.

Future course of research related to human error taxonomy may provide the possible outcomes,

1. Research findings will help the organizations to incorporate these findings in their safety training programs

2. Categorizing the errors, error mechanisms and developing a taxonomic error database will help the organizations to incorporate these findings in their safety training programs and it helps the safety management professionals and instructional designers to incorporate these findings related to human reliability aspects into safety manuals and instructional designs.

3. Research findings may help the system designers to design better human-machine feedback mechanisms by considering the human aspects in system's design to mitigate the human errors in safety critical domains. 


\section{REFERENCES}

[1] The Indian Factories Act 1948.

[2] Meister, D. (1966). Human factors in reliability. In W.G. Ireson (ed.) Reliability Handbook, New York: McGraw-Hill.Press, p. 29-37

[3] Swain, A.D. and Guttman, H.E. (1983). Handbook of Human Reliability Analysis with reference to Nuclear Power Plant Applications, Washington DC: U.S. Nuclear Regulatory Commission, pp. 2-7.

[4] Hollnagel, E. (1993). Human Reliability Analysis: Context and Control, London: Academic Academic Press, p. 29-38

[5] Reason, J., 1990. "Human Error". Cambridge University Press, Cambridge.

[6] Norman, D. The Psychology of everyday things. Doubleday New York, 1990

[7] Whittingham R.B, 'The Blame Machine why human error causes accidents', Elsevier Butterworth-Heinemanna, 2004

[8] Rasmussen, J., 1986. "Information Processing and Human-Machine Interaction. North-Holland, Amsterdam"

[9] Rasmussen, J., 1983. "Skills, rules and knowledge; Signals, Signs and Symbols and other distinctions in human performance models", IEEE transactions on systems, Man and Cybernetics, Vol-smc-13, No.3, May-1983. 